CZASOPISMO INŻYNIERII LACDOWEJ, ŚRODOWISKA I ARCHITEKTURY JOURNAL OF CIVIL ENGINEERING, ENVIRONMENT AND ARCHITECTURE

JCEEA, t. XXXIII, z. 63 (3/16), lipiec-wrzesień 2016, s. 59-66

Dariusz CZEKALSKI ${ }^{1}$

Martyna TOMASZEK ${ }^{2}$

\title{
ROZKŁAD NATEŻ̇ENIA PROMIENIOWANIA WZGLECDEM POŁUDNIA SŁONECZNEGO NA PŁASZCZYŹNIE POZIOMEJ W KWIETNIU I WE WRZEŚNIU
}

\begin{abstract}
Głównym celem pracy było porównanie sum promieniowania słonecznego docierającego do płaszczyzny horyzontalnej przed i po południu słonecznym. Dane do analizy statystycznej z wykorzystaniem testu Wilcoxona pochodzą ze stacji pomiarowej znajdującej się na terenie SGGW na warszawskim Ursynowie. Zakres danych obejmował miesiące kwiecień i wrzesień z lat 2005-2014. W obu miesiącach sumy promieniowania po południu były istotnie większe niż przed południem. $\mathrm{W}$ porównywanych dwóch parach godzin najbliższych południu słonecznemu nie było podstaw odrzucenia hipotezy o równości ich sum. Natomiast w czwartej i piątej parze godzin według hipotezy alternatywnej wyższe sumy promieniowania wystąpiły w części dnia po południu.
\end{abstract}

Słowa kluczowe: suma promieniowania słonecznego, godzina, połowa dnia, porównanie, test kolejności par

\section{Wprowadzenie}

Ilość energii promieniowania słonecznego docierającego do powierzchni ziemi jest kształtowana przez różne czynniki. Mają one charakter zarówno deterministyczny (współrzędne geograficzne miejsca, dzień kalendarza) jak też stochastyczny (cyrkulacja, stopień zachmurzenia, zmętnienie atmosfery). Położenie ma decydujący wpływ na wielkość i zmienność dopływu energii pochodzącej z promieniowania słonecznego. Polska zajmuje obszar pomiędzy równoleżnikami $49 \div 54^{\circ} \mathrm{N}$ i należy do strefy klimatu umiarkowanego przejściowego. Zachodnia strona kraju zdominowana jest przez czynniki związane z klimatem morskim. Wschodnia strona Polski wykazuje czynniki kontynentalne. Istotną

\footnotetext{
${ }^{1}$ Autor do korespondencji / corresponding author: Dariusz Czekalski, SGGW w Warszawie, Katedra Podstaw Inżynierii, ul. Nowoursynowska 166, 02-766 Warszawa; tel. 225934601; dariusz_czekalski@sggw.pl

${ }^{2}$ Martyna Tomaszek, SGGW w Warszawie, ul. Nowoursynowska 166, 02-766 Warszawa, studentka $2^{\mathrm{o}}$ studiów na kierunku Technologie Energii Odnawialnej
} 
rolę w kształtowaniu klimatu odgrywają oceaniczne masy powietrza, docierające na tereny Polski dwukrotnie w ciągu roku. Pierwszorzędną rolę odgrywają w sezonie jesienno-zimowym [1].

Decydującą rolę w tworzeniu zachmurzenia odgrywa cyrkulacja atmosfery. Najmniej korzystne warunki usłonecznienia, związane z największym zachmurzeniem występują podczas cyklonalnego typu cyrkulacji. Odwrotna sytuacja występuje, podczas cyrkulacji antycyklonalnej. Na terenie Polski zauważalna jest przewaga sytuacji antycyklonalnych nad cyklonalnymi. Wielkość zachmurzenia w Polsce determinowana jest w głównej mierze ciśnieniem atmosferycznym panującym nad danym obszarem oraz w jego pobliżu $[1,2,3]$. Według Wosia występują dwa typy dobowego rozwoju zachmurzenia:

- w okresie zimowym największe zachmurzenie występujące nad ranem lub w godzinach południowych, najmniejsze zaś wieczorem lub w nocy,

- w okresie letnim największe zachmurzenie notowane po południu, najmniejsze zaś wieczorem i w nocy [2, 4].

Zmienność cyrkulacji i zachmurzenia jest przyczyną wahań sum dobowych promieniowania słonecznego. Rysunek 1 przedstawia współczynniki zmienności sum dobowych napromieniowania płaszczyzny poziomej w Warszawie. Najmniejszy współczynnik zmienności wynoszący 34,8\% można zaobserwować w lipcu. Największy zaś odnotowano w listopadzie - 73,9\%. Generalnie okres letni charakteryzuje się najmniejszą zmiennością sum promieniowania.

Chwieduk [5] wykazała, że z punktu widzenia napromieniowania płaszczyzny nachylonej azymut jej powinien być odchylony od południa w kierunku zachodnim o $15^{\circ}$. Sugeruje to niesymetryczność napromieniowania względem kierunku górowania Słońca. Głównym celem opracowania jest próba odpowiedzi na pytanie czy dopływ promieniowania słonecznego w godzinach przed południem słonecznym różni się istotnie od notowanego po południu słonecznym. Rozpatrywana jest płaszczyzna horyzontalna, a dane pomiarowe pochodzą z lat 2005-2014 ze stacji znajdującej się na terenie Wydziału Inżynierii Produkcji przy ulicy Nowoursynowskiej w Warszawie. W prezentowanej fazie badań brany jest pod uwagę miesiąc kwiecień otwierający okres intensywnego pozyskiwania energii słonecznej miesiąc wrzesień okres ten zamykający.

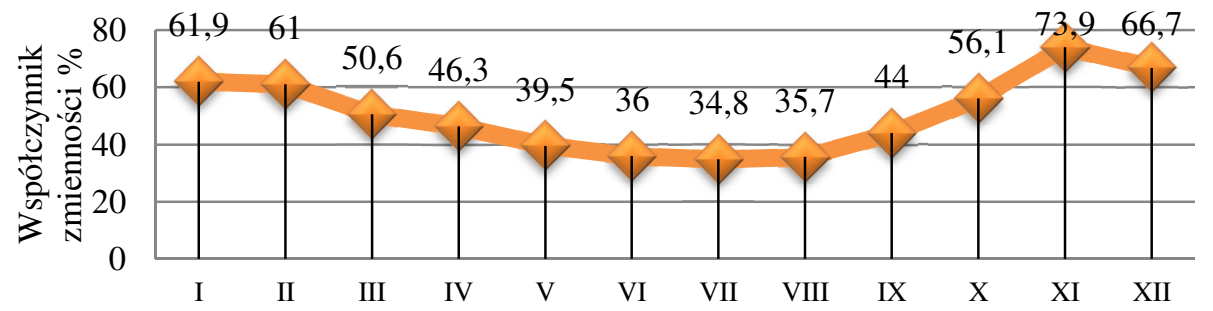

Rys. 1. Współczynnik zmienności dobowych sum promieniowania słonecznego na terenie Warszawy w latach 1961-1991, na podstawie [6]

Fig. 1. Coefficient of variation daily irradiation in Warsaw, years 1961-1991, based on [6] 


\section{Stanowisko badawcze i metodyka badań}

Stanowisko pomiarowe zlokalizowane na Wydziale Inżynierii Produkcji w Warszawie - Ursynów zostało oddane do użytku w 2005 roku. Głównym jego zadaniem jest pomiar natężenia promieniowania słonecznego na kilku płaszczyznach [7]. Jest ono wyposażone w urządzenia firmy Kipp\&Zonen. Na płaszczyźnie horyzontalnej wykorzystywany jest pyranometr CM 11 z podwójną kopułką. Przyrząd zaliczany jest do wzorców wtórnych. Sygnały pobierane z czujników ulegają przekonwertowaniu, a następnie rejestrowane są co minutę. Pomiary zamykane są o północy każdego dnia tworząc archiwizowane pliki.

Badana populacja, po usunięciu dni z awarią urządzeń, reprezentowana jest przez 231 próbek dla kwietnia i 283 próbki dla września. Celem analizy jest statystyczne uzasadnienie różnicy pomiędzy promieniowaniem docierającym na płaszczyznę poziomą przed i po południu słonecznym. Pierwszym etapem postępowania było obliczenie godziny urzędowej południa słonecznego dla każdego dnia. Następnie względem południa zostały wyznaczone pary godzin symetrycznie oddalone od południa słonecznego o jednakową liczbę godzin. W analizowanych miesiącach wygenerowanych zostało 5 par godzin [8].

Porównywane populacje zostały uznane za grupy zależne, ponieważ wysokość Słońca i droga, którą pokonuje jest jednakowa w porównywanych parach pochodzących z tych samych dni, a dany dzień generalnie charakteryzuje określona cyrkulacja. W takich uwarunkowaniach badanie istotności różnic wartości w danych parach można prowadzić testem t-Studenta, o ile próbki porównywane mają rozkłady normalne. Okazało się, że żadna z grup wartości sum promieniowania (całkowite sumy przed południem słonecznym; całkowite sumy po południu słonecznym oraz 5 grup godzinowych przed południem i 5 grup godzinowych po południu) nie mają rozkładów normalnych [8]. Wykazał to test Lilliefors'a, który jest poprawką do testu Kołmogorova-Smirnova. Test Kołmogorova-Smirnova nie mógł być bezpośrednio wykorzystany ze względu na brak znanego odchylenia standardowego oraz średniej populacji.

Wobec braku normalności rozkładów do analizy statystycznej wykorzystany został nieparametryczny test kolejności par Wilcoxona. Istotą tego testu jest zweryfikowanie hipotezy, czy mediana różnic badanych zmiennych jest równa 0 . Zgodnie z zasadami wnioskowania statystycznego stawia się hipotezę zerową $\left(\mathrm{H}_{0}\right)$ o równości wartości grupy porównywanych próbek, w tym teście o medianie różnic równej zero. Jeśli hipoteza zerowa zastaje odrzucona to przyjęta zostaje hipoteza alternatywna $\left(\mathrm{H}_{1}\right)$ mówiąca, że mediana różnic wartości badanych próbek w grupie jest różna od zera, a więc wartości sum promieniowania istotnie się różnią między sobą. We wnioskowaniu statystycznym błąd I rodzaju polega na odrzuceniu prawdziwej hipotezy zerowej. Prawdopodobieństwo popełnienia błędu I rodzaju nazywany jest poziomem istotności i oznaczany przez $\alpha$ (najczęściej przyjmowane wartości $\alpha$ to: 0,05 oraz 0,01 i 0,001 ). Przykładowo przyjęty $\mathrm{w}$ pracy poziom istotności równy $\alpha=0,5$ oznacza, że odrzucając $\mathrm{w}$ postępowaniu hipotezę zerową w 5 na 100 analiz może wystąpić błąd I rodzaju. 
Procedura testu Wilcoxona polega na rangowaniu różnic w wartościach pomiaru dla kolejnych obserwacji, czyli oblicza się w rozpatrywanym przypadku różnice pomiędzy sumą promieniowania przed i po południu słonecznym. Następnie różnice te szereguje się od najmniejszej do największej i nadaje się im kolejno rangi, osobno dla wartości dodatnich, osobno dla wartości ujemnych. Następnie zlicza się sumę rang dla różnic, które były ujemne i dla różnic, które były dodatnie. Mniejsza z otrzymanych sum to wartość statystyki testowej T testu Wilcoxona. Jeśli wartość statystyki T znaleziona w tablicach wartości krytycznych w funkcji liczebności próbek dla tego testu (w wersji przystosowanej do mniejszej z dwóch wartości sumy rang) odpowiada poziomowi istotności poniżej założonego (tu $\alpha=0,05$ ), to hipoteza $\mathrm{H}_{0}$ zostaje odrzucona i przyjęta alternatywna $\mathrm{H}_{1}$.Dla większej niż 25 liczby obserwacji różnice zmierzają do rozkładu normalnego. Wówczas oblicza się dodatkowo wartość statystyki Z testu Wilcoxona, czyli średnią różnic podzieloną przed odchylenie standardowe.

\section{Wyniki badań}

\subsection{Miesiąc kwiecień}

Dni wybrane do analizy dla kwietnia pochodziły z 9 lat (bez kwietnia 2011). Symetrycznie względem godziny południa słonecznego (między 12.33 , a 12.39 czasu CEST, zależnie od numeru dnia) wyznaczono sumy dzienne promieniowania przed południem $\mathrm{Q}_{\mathrm{ANTE}} \mathrm{i}$ popołudniu $\mathrm{Q}_{\mathrm{POST}}$. Sumy godzinowe promieniowania $\mathrm{w}$ pięciu parach symetrycznie oddalonych od południa oznaczono tak, że pierwsza sąsiadująca z południem para to przed południem $\mathrm{QI}_{\mathrm{A}}$ po południu $\mathrm{QI}_{\mathrm{P}}$. Kolejne pary oznaczono analogicznie: $\mathrm{QII}_{\mathrm{A}}$ i QII $\mathrm{itd}$.

Suma promieniowania słonecznego docierającego do powierzchni poziomej w kwietniu wynosiła średnio około $97 \mathrm{kWh} / \mathrm{m}^{2}$ (uwzględniając tylko 10 centralnych godzin dnia). Suma promieniowania po południu słonecznym, stanowiła około $51 \%$ całkowitego promieniowania $\mathrm{z}$ pięciu par godzin słonecznych (rys. 2). Test Wilcoxona rozstrzygnął czy różnica jest istotna statystycznie.

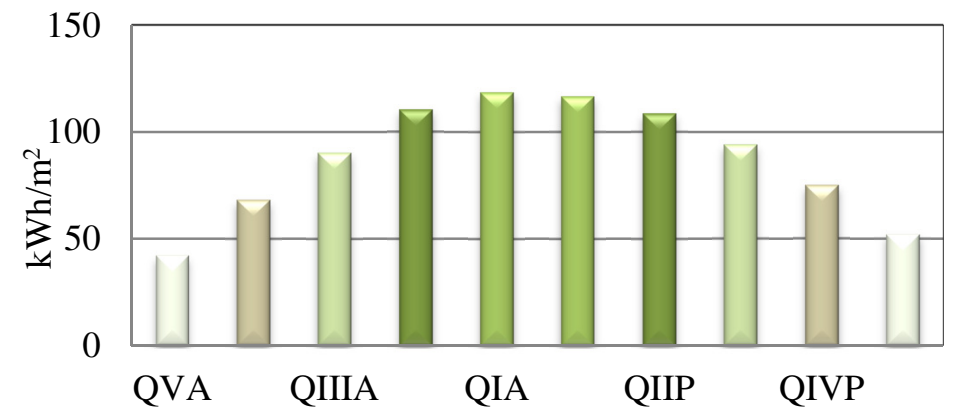

Rys. 2. Rozkład sum promieniowania słonecznego na godziny dnia w kwietniu

Fig. 2. Hourly distribution of solar radiation in April 
W tabeli 1 uzupełnionej wykresem ramka-wąsy (rys. 3) zawarto obliczenia wskaźników testu. Mniejsza z sum rang przy 231 próbkach w grupie oznacza poziom istotności 0,0076 , czyli zdecydowanie poniżej założonego $\alpha=0,05$. Hipoteza o równości sum promieniowania przed i po południu słonecznym w kwietniu zostaje odrzucona, a przyjęta hipoteza alternatywna o istotnej statystycznie różnicy między sumami. Ujemna mediana różnic wskazuje, że sumy promieniowania w drugiej części dnia są wyższe.

Tabela 1. Wyniki testu Wilcoxona dla sum promieniowania przed i po południu dla kwietnia

Table 1. Wilcoxon's test results for ante and post noon half-daily solar radiation in April

\begin{tabular}{|c|}
\hline Test Wilcoxona dla grup zależnych \\
\hline Analizowane zmienne $Q_{\text {ANTE}} ; Q_{\text {POST }}$ \\
\hline Poziom istotności 0,05 \\
\hline $\begin{array}{l}\text { Nazwa grupy } Q_{\text {ANTE }} \\
\text { Liczebność grupy } 231 \\
\text { Mediana grupy, Wmin } / \mathrm{m}^{2} 117167\end{array}$ \\
\hline $\begin{array}{l}\text { Nazwa grupy QPosT } \\
\text { Liczebność grupy } 231 \\
\text { Mediana grupy, Wmin } / \mathrm{m}^{2} 118360\end{array}$ \\
\hline $\begin{array}{l}\text { Liczebność - ilość par } 231 \\
\text { Mediana różnic, Wmin/m² -7037 } \\
\text { Mniejsza suma rang } 10691\end{array}$ \\
\hline $\begin{array}{l}\text { Statystyka T } 10691 \\
\text { Wartość p (dokładna) 0,007609 } \\
\text { Statystyka Z -2,66228 } \\
\text { Wartość (asymptotyczna) 0,007761 }\end{array}$ \\
\hline
\end{tabular}

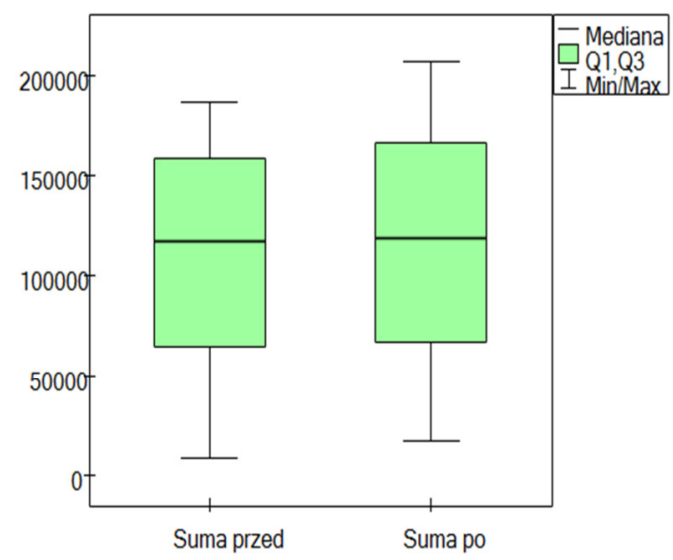

Rys. 3. Wykres ramka-wąsy porównywanych grup sum promieniowania dla kwietnia

Fig. 3. Box-and-whisker plots of half-daily solar radiation data in April

Porównanie sum godzinowych promieniowania w godzinach bezpośrednio poprzedzającej południe słoneczne i następującej po nim wykazało, że nie ma podstaw do odrzucenia hipotezy braku różnic w grupach $-\mathrm{H}_{0}$. Dokładny poziom istotności przekracza wielokrotnie przyjętą wartość 0,05 (tab. 2). Badając kolej-

Tabela 2. Charakterystyka porównywanych par sum godzinowych promieniowania i wyniki testu Wilcoxona (kwiecień)

Table 2. Compared pairs of hourly solar radiation data and Wilcoxon's test results (for April)

\begin{tabular}{|l|c|c|c|c|c|}
\hline \multirow{2}{*}{$\begin{array}{c}\text { Parametr } \\
\text { testu }\end{array}$} & \multicolumn{5}{c|}{ Porównywane grupy } \\
\cline { 2 - 6 } & $\mathrm{QI}_{\mathrm{A}} / \mathrm{QI}_{\mathrm{P}}$ & $\mathrm{QII}_{\mathrm{A}} / \mathrm{QII}_{\mathrm{P}}$ & $\mathrm{QIII}_{\mathrm{A}} / \mathrm{QIII}_{\mathrm{P}}$ & $\mathrm{QIV}_{\mathrm{A}} / \mathrm{QIV}_{\mathrm{P}}$ & $\mathrm{QV}_{\mathrm{A}} / \mathrm{QV}_{\mathrm{P}}$ \\
\hline $\begin{array}{l}\text { Mediana grupy } \\
\text { Wmin/m }\end{array}$ & $\begin{array}{c}33282 / \\
30834\end{array}$ & $\begin{array}{c}31736 / \\
28935\end{array}$ & $\begin{array}{c}25522 / \\
24522\end{array}$ & $\begin{array}{c}18324 / \\
19929\end{array}$ & $\begin{array}{c}10739 / \\
13260\end{array}$ \\
\hline $\begin{array}{l}\text { Mediana różnic, } \\
\text { Wmin/m }\end{array}$ & -478 & -997 & -1915 & -1982 & -3070 \\
\hline Statystyka T & 13280 & 13343 & 11580 & 9860 & 6940 \\
\hline Wartość p & 0,90817 & 0,95719 & 0,07382 & 0,000465 & 0,00010 \\
\hline
\end{tabular}


ne pary godzin symetrycznie oddalonych od południa słonecznego wnioskowano na podstawie testu Wilcoxona, że nie ma podstaw do odrzucenia hipotezy o braku różnic w grupach dla pierwszej, drugiej i trzeciej pary godzin. Natomiast istotne statystycznie różnice wystąpiły dla czwartej i piątej pary godzin, oddalonych o 4 i 5 godzin od południa słonecznego (tab. 2).

\subsection{Miesiąc wrzesień}

Do analizy statystycznej dla września wybrano 283 dni z lat 2005-2014. Suma promieniowania słonecznego na płaszczyźnie horyzontalnej we wrześniu w okresie 10 lat wynosiła średnio około $91 \mathrm{kWh} / \mathrm{m}^{2}$ (uwzględniając tylko 10 centralnych godzin dnia). Suma promieniowania w połowie dnia po południu słonecznym (godzina południa słonecznego wg czasu CEST wypadała między 12.25, a 12.36, zależnie od dnia miesiąca) stanowiła $50,62 \% \mathrm{z}$ całego dnia. Test Wilcoxona rozstrzygnął, że jest to różnica istotna statystycznie (tab. 3), ponieważ hipoteza o równości sum została odrzucona $(\mathrm{p}<<0,05)$. Mediana różnic wskazuje na to, że to sumy po południu słonecznym są wyższe.

Badając kolejne pary godzin symetrycznie oddalonych od południa słonecznego we wrześniu wnioskowano na podstawie testu Wilcoxona, że nie ma podstaw do odrzucenia hipotezy o braku różnic w grupach dla pierwszej i pary godzin. Natomiast istotne statystycznie różnice wystąpiły w trzeciej, czwartej i piątej parze godzin, oddalonych odpowiedni o 3, 4 i 5 godzin od południa słonecznego (tab. 3).

Tabela 3. Charakterystyka pięciu porównywanych par sum godzinowych promieniowania i wyniki testu Wilcoxona we wrześniu

Table 3. Compared pairs of hourly solar radiation data and Wilcoxon's test results (for September)

\begin{tabular}{|l|c|c|c|c|c|c|}
\hline \multirow{1}{*}{\begin{tabular}{c}
\multirow{1}{*}{$\begin{array}{c}\text { Parametr } \\
\text { testu }\end{array}$} \\
\cline { 2 - 7 }
\end{tabular}} & $\begin{array}{c}\mathrm{Q}_{\mathrm{ANTE}} / \\
\mathrm{QPOST}\end{array}$ & $\begin{array}{c}\mathrm{QI}_{\mathrm{A}} / \\
\mathrm{QI}_{\mathrm{P}}\end{array}$ & $\begin{array}{c}\mathrm{QII}_{\mathrm{A}} / \\
\mathrm{QII}_{\mathrm{P}}\end{array}$ & $\begin{array}{c}\mathrm{QIII}_{\mathrm{A}} / \\
\mathrm{QIII}_{\mathrm{P}}\end{array}$ & $\begin{array}{c}\mathrm{QIV}_{\mathrm{A}} / \\
\mathrm{QIV}_{\mathrm{P}}\end{array}$ & $\begin{array}{c}\mathrm{QV}_{\mathrm{A}} / \\
\mathrm{QV}_{\mathrm{P}}\end{array}$ \\
\hline $\begin{array}{l}\text { Mediana grupy } \\
\text { Wmin/m }\end{array}$ & $\begin{array}{c}103249 / \\
101657\end{array}$ & $28677 /$ & $28635 /$ & $23390 /$ & $15851 /$ & $6905 /$ \\
28417 & 26145 & 23179 & 16835 & 9925 \\
\hline $\begin{array}{l}\text { Mediana różnic, } \\
\text { Wmin/m }\end{array}$ & -4978 & -387 & 101 & -1272 & -1535 & -2562 \\
\hline Statystyka T & 16062 & 20087 & 18537 & 17082 & 15920 & 9256 \\
\hline Wartość p & 0,00335 & 0,99655 & 0,25940 & 0,02875 & 0,02381 & 0,00010 \\
\hline
\end{tabular}

\section{Analiza wyników badań}

Analiza statystyczna sum promieniowania słonecznego w kwietniu w latach 2005-2014 wykazała niewielką, ale istotną statystycznie przewagę sum promieniowania po południu słonecznym. Test przeprowadzony dla par w poszczególnych godzinach nie był tak jednoznaczny. $W$ trzech pierwszych parach godzin 
w sąsiedztwie południa, nie stwierdzono istotnej różnicy kształtującej przewagę sum promieniowania po południu słonecznym. Dwie pary godzin najbardziej oddalone od południa słonecznego determinują przewagę sum promieniowania po południu słonecznym. Analiza statystyczna sum promieniowania słonecznego we wrześniu w latach 2005-2014 wskazała istotną przewagę sum promieniowania po południu słonecznym. Największy wpływ na kształtowanie tej przewagi mają pary godzin oddalonych symetrycznie od południa słonecznego o 3, 4 i 5 godzin. W dwóch pierwszych godzinach w sąsiedztwie południa słonecznego sumy promieniowania nie wykazują istotnych różnic.

Trudno jest przedstawić prostą teorię charakteryzującą powstawanie zachmurzenia i wyjaśniającą wykryte zależności. Analizy wymaga m. in. rozkład czasowy zawartość wilgoci, ozonu oraz pyłów zawieszonych w powietrzu w dzielnicy Ursynów. Badania kontynuowane będą w kierunku statystycznej oceny zawartości składników atmosfery wpływających na jej zmętnienie przed i po południu słonecznym. Wstępna ocena (bez instrumentów statystycznych) dotyczyła stężenia pyłu zawieszonego PM10 w dzielnicy Ursynów (stacja Wojewódzkiego Inspektoratu Ochrony Środowiska). Stężenie pyłów zostało sprawdzone o godzinie 9:00 oraz o16:00. Godziny te zawierały się w przedziale mającym istotny wpływ na przewage sum promieniowania po południu słonecznym. Przykładowo w kwietniu 2012 roku stężenie pyłu zmierzone o godzinie 9:00 było o około 40\% wyższe niż o godzinie 16:00. Generalnie dzienna zawartość pyłów przed południem słonecznym była we wrześniu, tak jak i w kwietniu, wyraźnie większa przed południem słonecznym, co może być przyczyną zmniejszenia wtedy sumy promieniowania słonecznego.

\section{Podsumowanie}

Analiza rozkładu promieniowania słonecznego przed i po południu słonecznym opierała się na pomiarach na stacji, znajdującej się na terenie SGGW w Warszawie. Przewaga sum promieniowania po południu słonecznym w kwietniu i we wrześniu okazała się istotna statystycznie. Odchylenie od azymutu południowego $\mathrm{w}$ kierunku zachodnim w przypadku płaszczyzn nachylonych znajduje tym samym dodatkowe uzasadnienie. Dalsze badania według analogicznej metodyki będą dotyczyć miesięcy od maja do sierpnia, a także sum promieniowania na płaszczyźnie nachylonej.

\section{Literatura}

[1] Kożuchowski K.: Klimat Polski, nowe spojrzenie, PWN, Warszawa 2011.

[2] Matuszko D.: Wpływ zachmurzenia na usłonecznienie i całkowite promieniowanie słoneczne na przykładzie krakowskiej serii pomiarów, Uniwersytet Jagielloński, Kraków 2009. 
[3] Żmudzka E.: Zmienność zachmurzenia nad Polską i jej uwarunkowania cyrkulacyjne, Wydawnictwo Uniwersytetu Warszawskiego, Warszawa 2007.

[4] Woś A.: Klimat Polski w drugiej połowie XX wieku, PWN, Warszawa 2010.

[5] Chwieduk D.: Modelowanie i analiza pozyskiwania oraz konwersji termicznej energii promieniowania słonecznego w budynku, rozprawa habilitacyjna, IPPT PAN, Warszawa 2006.

[6] Bogdańska B., Podogrocki J.: Zmienność całkowitego promieniowania słonecznego na obszarze Polski w okresie 1961-1995, IMiGW, Warszawa 2000.

[7] Chochowski A., Czekalski D., Obstawski P.: Pomiary pyranometryczne na stanowisku SGGW - Ursynów. Polska Energetyka Słoneczna nr 2, 2005.

[8] Krassowska M.: Rozkład dobowego natężenia promieniowania słonecznego na płaszczyźnie poziomej w miesiącu kwietniu i wrześniu w latach 2005-2014, SGGW, praca inżynierska, Warszawa 2015.

\section{DISTRIBUTION OF SOLAR RADIATION IN RELATION TO SOLAR NOON ON HORIZONTAL SURFACE IN APRIL AND SEPTEMBER}

\section{S u m m a r y}

In this paper, we present comparison between a global solar radiation on a horizontal surface before and after solar noon. Ten years (2005-2014) data from meteorological station located within campus SGGW - Warsaw were used. April and September data were selected for analysis. We have used statistical Wilcoxon's test to compare sums of solar radiation for statistical differences. Solar radition after noon is significant higher than before one, both the months. With regard to first and second pair nearest noon hours, there were no evidence to reject hypothesis about equality of hourly solar radiation before and after solar noon. However, in the fourth and fifth pair of hours, were accepted alternative hypothesises - hourly solar radition after noon is significant higher than before one.

Keywords: half-daily solar radiation, hourly solar radiation, comparison, paired difference test

DOI: $10.7862 / \mathrm{rb} .2016 .186$

Przestano do redakcji: $30.06 .2016 r$.

Przyjęto do druku: $30.11 .2016 r$. 